\title{
Are we progressing towards elimination of diphtheria, pertusis, tetanus from Nepal?
}

\author{
Jha $\mathbf{N}^{1}$, Kumar $\mathbf{S}^{2}$ \\ ${ }^{1}$ Professor, ${ }^{2}$ Associate Professor, Department of Community Medicine, BP Koirala Institute of Health Sciences, Dharan, \\ Nepal
}

\begin{abstract}
Diphtheria, Pertussis and Tetanus (DPT) are the vaccine preventable diseases of childhood. The published literatures and reports related to DPT immunization coverage are relatively more than DPT diseases. The striking reduction in deaths and in the incidence of these diseases has been closely associated with the introduction of specific vaccination program. Expanded Program on Immunization (EPI) is a priority program in the country. Nepal has been running country-wide immunization program since 1989. However, there is no doubt that the program has contributed significantly towards reduction of infants and child mortality. Effective and efficient surveillance system and strengthening the routine immunization against DPT are the key steps for elimination of DPT diseases.
\end{abstract}

Key words: DPT, Diphtheria, Pertussis, Tetanus, Immunization, DPT Vaccine, surveillance, vaccine coverage, Nepal.

$\mathrm{D}$ iphtheria, Pertussis and Tetanus (DPT) are the vaccine preventable diseases of childhood. Diphtheria is an acute bacterial disease involving primarily tonsils, pharynx, larynx and nose of the non-immunized children less than 15 years of age. Pertussis is another acute bacterial disease involving the respiratory tract of the young children.

Tetanus is also an acute disease induced by an exotoxin of the bacteria. The disease is characterized by painful muscular contractions, primarily of the masseter and neck muscles, and secondarily of the trunk muscles. A common first sign suggestive of tetanus in older children and adult is abdominal rigidity ${ }^{1}$.

Diphtheria, still occasionally seen in many South East Asian countries including Nepal and India is thought to be declining in these areas. However, accurate data have not been recently available particularly from Nepal, because reporting is infrequent, laboratory confirmation is not available and the extent of carrier is not clearly known.

Infant of women who did not receive any tetanus vaccination during pregnancy was more likely to die in neonatal period. The protection from neonatal deaths afforded by tetanus vaccination may be due in part to the direct protection of the infant from neonatal tetanus (NNT). The greatest protection is conferred during the peak period for neonatal tetanus deaths ${ }^{2}$.

\section{DPT Diseases}

It has been reported in the country report, the incidence rates of Diphtheria 14.5, Pertusis 436.6 and Tetanus 5.9 per 100,000 populations in Nepal. The author has further reported the incidence rate of Neonatal tetanus as 21.9 per 1000 live births ${ }^{3}$.

Nepal/Net Kids Sociology and Childhood diseases 2004 showed an annual prevalence of diphtheria as 14.5 per 100,000 populations in the year 1983. In Kanti Children's Hospital Katmandu, seven cases of diphtheria were reported in 1983/84 and only one case in $1988 / 89^{4}$. The prevalence rate for pertussis was 436 per 100,000 populations in same year ${ }^{4}$.

A survey conducted by Ministry of Health $(\mathrm{MOH})$ showed that 15 of 37 neonatal deaths per 1000 live births were caused by neonatal tetanus ${ }^{4}$. Another survey conducted in 1983 showed that tetanus was cause of death in 55\% neonate in rural Nepal. The Katmandu valley survey gave a rate of $50 \%$. A later survey in Morang district in eastern Nepal showed a drop to $23 \%$ of neonatal deaths. This may be due to in part to better immunization coverage rates and better practices among birth attendants. Data indicate a $75 \%$ reduction in neonatal tetanus within eight years of starting the

\section{Correspondence}

Professor Nilambar Jha

Department of Community Medicine

BP Koirala Institute of Health Sciences, Dharan, Nepal

E-mail: niljha@yahoo.com 
national immunization program. A sharp drop in the number of cases reported in 1989, gives further evidence of the success of immunization and safe delivery practices. Reported prevalence of neonatal tetanus and all forms of tetanus was highest in the terai districts of the far western Nepal.

WHO has reported DPT cases in Immunization Profile - $\operatorname{Nepal}^{5}$ (Table 1).

The annual pertussis and diphtheria incidence (cases per 100,000 persons) for all age has shown constant decrease for both diseases. But there were two peaks for pertussis in 1995 and 1997. These peaks might be due to epidemics in those years. Diphtheria showed constant declining trend from 1994 through 2002 (Table 2) .

These data however should be interpreted cautiously, because in many cases, no case definition has been used in the diagnosis of the diseases. Reported data from the past three years indicate a sharp decline in pertussis cases from $63 / 10,000$ in 1998 to $26 / 10,000$ population in 2002 and similarly overall incidence rate of diphtheria declining from 2.2/10,000 in 1998 to $1.6 / 10,000$ in 2002. Since most of the health workers are not trained on case definition and a system for laboratory confirmation is lacking it is difficult to estimate the true burden. The annual reports of $\mathrm{MOH}$ indicate a sharply decreasing trend of neonatal tetanus cases from 727 cases in 1995 to 50 cases in $1999^{4}$. These data give the false impression of very low incidence rate for neonatal tetanus. Considering the nature of the disease as a 'silent killer' and in view of the fact that over $90 \%$ of deliveries in Nepal take place at home under unhygienic conditions, without the assistance of trained health care providers, most likely many cases go unnoticed.

Most realistic figures are difficult to come, but an indication of the seriousness of the situation may be found in the 1996 Nepal Multiple Indicator Survey. This survey reports that $15 \%$ of the village health workers and $16 \%$ of female community health volunteers had encountered a case in the past one year ${ }^{7}$. With 42,000 female community health volunteers active nation wide, this would indicate over 6700 cases of neonatal tetanus per year (or 8/1000 live births).

Nepal has been providing immunization service country wide for over more than ten years. There is good surveillance system for VPDs.

A five year sentinel surveillance from rural India showed that there were no significant change of diphtheria cases as well as more than $3 / 4^{\text {th }}$ cases in less than two years age group ${ }^{8}$. In early nineties in India it was estimated that more than 3.5 lakh children died annually due to
NNT that decreased to more than 70,000 in the year 93-94. These changes may be due to implementation of National Immunization Program ${ }^{9,10}$. A sharp decline in pertussis cases were also seen during 1987 to 2000 . The reported incidence was about 1.63 lakhs in 1987 compared to only 26.7 thousand in the year 2000 in India9.

\section{DPT Immunization Coverage}

Knowing immunization coverage is as important as knowing the disease/cases for Vaccine preventable diseases (VPDs). This gives an idea of population that is prone to get disease and comparatively less prone population. It has been reported that the coverage for DPT2 immunization was $57 \%$ and $23.1 \%$ in Surkhet and Banke districts of mid western Nepal. Similarly DPT3 coverage was $56.8 \%$ and $22 \%$ in these above districts ${ }^{11}$. On comparison, Surkhet district showed better coverage than Banke, but both districts showed less immunization coverage than EPI estimates by the Government. There were strong positive associations between immunization coverage and type of health post and literacy level of mothers. The problems stated by health workers for less immunization coverage is due to improper immunization services related to lack of it in static health post, inadequate staff to conduct services in the camps, poor awareness among the mothers, lack of vaccines and inadequate educational activity. It was surprising that better transport facility did not ensure better coverage for Banke district (with better transport facility) compared to Surkhet district.

Another study has been done to find out the knowledge on immunization at Kanti Children's Hospital, Kathmandu among the mothers of inpatient children under five years of age. They have reported only $34 \%$ mothers knew the correct age for starting DPT immunization. Twenty percent mothers did not know the place for child immunization. Their main source of information was from health personnel $(55 \%)^{12}$.

Report on DPT immunization coverage by WHO in different years in Nepal has been given in the Table ${ }^{4}$. (Table 3).

The above data shows that there is difference between DPT1 and DPT3 coverage. DPT3 coverage is lower. The high drop-outs could be due to poor service delivery, lack of knowledge among the parents about subsequent doses to complete the series. Another important point mentioned in this profile is the proportion of district reporting DPT coverage. Greater or equal to $80 \%$ DPT3 coverage was reported by $44 \%$ districts. Forty-nine percent districts reported DPT3 coverage from 50 to $79 \%$. Similarly $7 \%$ districts informed less than $50 \%$ DPT3 coverage. 
The DPT3 immunization coverage in Nepal as reported was between 75 to $80 \%$ from the year 1994 to $2002^{6}$. This coverage was among the children less than one year old. These data are again health facility based. Various surveys have shown that the actual coverage is lower than the reported coverage by $5-15 \%$.

World Bank reported that there was significant change in DPT3 coverage in low and middle income countries ${ }^{13}$. The figures are given in Table 4.

In Peru the Immunization coverage of DPT3 showed significant improvement from around $70 \%$ in 1986 to almost $90 \%$ in 1998. But there were not remarkable change in Egypt from $70 \%$ in 1988 to $80 \%$ in 1995. The DPT coverage has been as low as $25 \%$ in Niger and as high as $96 \%$ in Uzbekistan and Jordan according to World Bank in mid nineties ${ }^{13}$.

In India there were gross difference in DPT immunization coverage among areas served under Integrated Child Development Services (ICDS) and non ICDS. The survey revealed that coverage was $63 \%$ in ICDS served area as compared to only $28 \%$ in non served area in $1988^{14}$. It has been noticed that drop out is common from DPT 1 and DPT3. A survey revealed that the drop out was $1 \%$ among urban children as compared to $8 \%$ in rural children ${ }^{15}$. It was observed that availability of vaccines throughout the week and easy access even on payments had important role in achieving higher level of coverage in town as compared to area where all vaccines are given by government ${ }^{16}$.

Table 1: Number of DPT cases in different years in Nepal.

\begin{tabular}{|c|c|c|c|c|c|c|c|}
\hline \multirow{2}{*}{ Name of Diseases } & \multicolumn{7}{|c|}{ Years } \\
\hline & 1980 & 1990 & 1997 & 1998 & 1999 & 2000 & 2001 \\
\hline Diphtheria & 82 & 7 & 726 & 511 & NA & 268 & 390 \\
\hline Pertussis & 1055 & 18 & 12443 & 14339 & NA & 6021 & 5908 \\
\hline Neonatal Tetanus & NA & 0 & 462 & 197 & NA & 134 & 327 \\
\hline All type of Tetanus & 116 & 35 & 574 & 556 & 349 & 305 & 440 \\
\hline
\end{tabular}

NA=Not Available

Table 2: Annual incidence rates (cases per 100,000) of diphtheria and pertussis form Annual Reports, 1994 to $2002^{6}$.

\begin{tabular}{|l|c|c|c|c|c|c|c|c|c|}
\hline Diseases & 1994 & 1995 & 1996 & 1997 & 1998 & 1999 & 2000 & 2001 & 2002 \\
\hline Diphtheria & 20 & 10 & 6 & 5 & 3 & 3 & 1.6 & 1.5 & 1 \\
\hline Pertussis & 50 & 90 & 60 & 64 & 38 & 28 & 25 & 20 & 18 \\
\hline
\end{tabular}

Table 3: Percentage of population vaccinated in different years

\begin{tabular}{|l|c|c|c|c|c|c|c|}
\hline Vaccines & 1980 & 1990 & 1997 & 1998 & 1999 & 2000 & 2001 \\
\hline DPT3 & 8 & 80 & 78 & 76 & 76 & 80 & 72 \\
\hline DPT1 & NA & NA & NA & NA & NA & 91 & 84 \\
\hline
\end{tabular}

NA $=$ Not Available

Table 4: DPT3 coverage according to World Bank report

\begin{tabular}{|l|c|c|c|c|c|c|c|c|c|c|}
\hline Vaccines & 1980 & 1982 & 1984 & 1986 & 1988 & 1990 & 1992 & 1994 & 1996 & 1997 \\
\hline DPT3 & 39.5 & 45.7 & 51.6 & 58 & 65.4 & 76.9 & 76.1 & 77.2 & 80.2 & 80.3 \\
\hline
\end{tabular}


Child Health Division has published a comprehensive overview about present situation of immunization coverage and its short comings and steps to be taken for the improvements in 'Immunization program in Nepal, Multi year plan of action, 2001 to 2005'. Few important observations are given below ${ }^{17}$.

1. Expanded Program on Immunization (EPI) is a priority program in Nepal. It has been running countrywide since 1989 . The disease surveillance system is weak; therefore it is difficult to measure the impact. However, there is no doubt that the program has contributed significantly towards the reduction of infant and child mortality.

2. Nepal introduced immunization with six primary series antigens to all 75 districts only in 1989. In 1990 , the coverage was increased to $80 \%$ except for measles through massive campaigns. However, the coverage gained through these campaigns could not sustain and the following years saw a steady decline in the coverage. This trend continued until 1994. From 1995, the coverage started to improve, and since 1998, the overall coverage has stabilized at around $76 \%$.

3. Three independent coverage ${ }^{18,19}$ surveys confirm the improving trend, but also show that the official reporting is higher than the actual coverage believed to be due to underestimation of target population. The Health Management Information System (HMIS) estimates a target population based on the projected population of 1991 census and does not take into consideration factors such as migration. The patterns of inconstant reporting from districts raise the question of reliability of the routine data.

4. The HMIS report for 2000 indicates a slight improvement with $80 \%$ DPT3 coverage compared with $76 \%$ in 1999 . Between Census Household Information Monitoring and Evaluation Survey (BCHIMES) 2000 indicates no gender disparity in the initial dose of DPT1. However dropout rates for girls are slightly higher than that of boys in DPT3, indicating that fewer girls complete the immunization series than boys. Though small, the fact that the difference exists is the matter of concern ${ }^{20}$.

5. The 1998 coverage survey conducted jointly by Child Health Division, UNICEF and WHO indicated that the program has reached 92\% of the total target population with one or more immunization doses. However, only $65 \%$ children completed the full series by age one. The high dropouts rate is attributed to "lack of proper service" and "parents limited knowledge about the importance of completing series".
Eight percent of the target population was not reached, probably due to socio- economic condition and remoteness of the communities. Coverage in the southern terai districts at $58 \%$ was much lower than hills and mountain districts at $70 \%{ }^{18}$.

Two diphtheria cases reported from BPKIHS, Dharan did not give a complete history of immunization and may not have been vaccinated with DPT vaccine ${ }^{21}$.

An Indian experience shows that only $50 \%$ of the diphtheria cases were immunized with two doses of DPT vaccine ${ }^{22}$. The percentage coverage with three doses of the DPT vaccine varied between $27 \%$ to $88.5 \%$ in different states in India ${ }^{23}$. Lack of sustained immunization may even result in outbreaks.

Though, the immunization program against DPT diseases has made significant progress over the years, VPDs still cause many children deaths. Currently, incomplete case reporting and inaccurate coverage reporting in Nepal tends to over-estimate the impact and the success of the immunization program.

$\mathrm{MOH}$ has committed to improve the routine immunization program. In 1999, with UNICEF and WHO support, the $\mathrm{MOH}$ revised the National Immunization Policy, providing a long-term vision and operational strategies to improve the routine immunization program. The new policy document outlines the objectives, targets, and strategies for Nepal's national immunization program. It takes in to account recent developments in immunization strategies, and current limitations of the program.

The revised strategy for immunization program has focused on following major areas: increasing the accessibility to services, improving the quality of services, promoting safe injection practices, high risk area approach for neonatal tetanus elimination, exploring the introduction of new vaccines, decentralized planning and community partnership in the management of immunization sessions.

\section{Conclusion and recommendation}

The surveillance system for all VPDs is good \& they run jointly under polio.

It is important to have reliable system of district, regional and national level surveillance to assess the burden of diseases (death, disability and cost) and the effect of the proposed program. Good surveillance is also required to monitor both the ongoing effect existing program and any vaccine related adverse events. 
The published literatures and reports related to DPT immunization coverage are relatively more than DPT diseases. The striking reduction in deaths and in the incidence of these diseases has been closely associated with the introduction of specific vaccination program. EPI is a priority program in the country. Nepal has been running country- wide immunization program since 1989. However, there is no doubt that the program has contributed significantly towards reduction of infants and child mortality.

Effective and efficient surveillance system and strengthening the routine immunization against DPT are the key steps for elimination of DPT diseases.

\section{Future Challenges}

The future challenges include the followings:

1. The culture of prevention of diseases using vaccination must be fostered. This involves increasing the awareness, focusing on disease elimination / eradication through vaccination, disease surveillance, and mobilizing the needed resources.

2. The challenges of service delivery would mean reaching the under-reached and un-reached population. Apart from geographical access, one needs to look into bias and socio-cultural barriers and beliefs to understand the reasons for non-participation. Additional efforts, as demanded by epidemiological considerations, need to be thoroughly planned and executed.

3. Immunization coverage is not encouraging in mid and far western regions of the country especially in terai belts. Additional efforts will be required to step up the coverage in these areas. Monitoring the reported coverage and the discrepancy between the reported and evaluated coverage should become an effective advocacy tool.

4. Communication and social mobilization for the prevention of VPDs should be taken as a big challenge, especially in the areas, which have not been able to achieve universal child immunization. Ensuring the human rights of all children, especially the unreached calls for an understanding of the non-participation by certain families and suitable mobilization efforts.

\section{References}

1. BenensonAS (editor). Control of Communicable Diseases Manual. $16^{\text {th }}$ edition. London,UK 1995.

2. Kartz J, West KP and Khatry SK et al. Risk factors for early infant mortality in Sarlahi district, Nepal. Bulletin of World Organization 2003;81(10):717-25.
3. Rana B. Country Report - Nepal. In: WHO. The Expanded Program on Immunization in South -East Asia, WHO, SEARO. SEARO, Delhi; 1986. P. 191-203.

4. Nepal/Net Kids Sociology and Demography Childhood Diseases. Kathmandu: 2004.

5. WHO. WHO Immunization profile - Nepal, vaccine - preventable diseases monitoring system 2002 global strategy. Geneva: WHO; 2002.

6. DOHS. Health management Information system, Department of Health Services, Kathmandu. Annual Reports 1994 2002. Kathmandu:Department of Health Services;2002.

7. National Planning Commission and UNICEF. NMIS survey1998. Kathmandu: NMIS;2000.

8. Ray SK, Dasgupta S, Saha I. Areport of diphtheria surveillance from rural medical college hospital. J Ind Med Assoc. 1998;96(8):236-8.

9. Park K. Parks textbook of preventive and social medicine. $18^{\text {th }}$ Edition.Jabalpur: Banarsidas Bhanot publishers; 2000.

10. Sokhey J, Bhargva I. Control of neonatal tetanus in India. Ind Paedtr 1984;21(7):515-9.

11. Shrestha IB. Immunization status survey in midwestern region of Nepal. In: Health research abstracts (1991 - 1994) companion volume of proceedings of second National Seminar on health research in Nepal / Nepal Health Research Council, Kathmandu. Kathmandu: Nepal Health Research Council; 1995. P. 26-9.

12. Lohani DN and Shrestha S. Mother's knowledge about immunization schedules. Proceedings of second National Seminar on health research in Nepal / Nepal Health Research Council, Kathmandu. Kathmandu: Nepal Health Research Council; 1995. P. 13-4.

13. World Bank. DPT coverage. [Homepage on the internet]. [Cited 2008 May 20]. Available from: www.siteresource.worldbank.org.

14. Tandon BN, Gandhi N. Immunization coverage in India for areas served by Integrated Child Development Services Program. Buul of WHO 1992;70(4):461-5.

15. Dhadwal D, Sood R, Gupta AK, Ahluwalia SK, Vatsayan A, Sharma R. Immunization coverage among urban and rural children in the Simla hills. J Commun Dis 1997;29(2):127-30.

16. Balraj V, Mukundan S, Samuel R, John TJ. Factors affecting immunization coverage level in a district of India. Int J Epid 1993;22(6):114653. 
17. Child Health Division, Department of Health Services, Ministry of Health, Kathmandu. Immunization program in Nepal, Multi year plan of action 2001-2005. Kathmandu: Department of Health Services; 2005.

18. Child Health Division, UNICEF and WHO. National Immunization Coverage Survey 1998. Kathmandu: UNICEF \& WHO; 2000.

19. Department of Health Services and MII. Nepal Family Health Survey 1996. Kathmandu: Department of Health Services; 1998.

20. National Planning Commission, Bureau of Statistics and UNICEF. Between Census Household Information Monitoring and evaluationsurvey2000March-May.Kathmandu: National planning commission;2001.
21. Srinivasa H, Parija SC and Upadhyay MP. Diphtheria in eastern Nepal. Emerg Infect Dis.1999 March - April;5(2):304-5.

22. Lodha R, Dash NR, Kapil A and Kabra SK. Diphtheria in urban slums in north India. The Lancet 2000;355:204.

23. Singhal T, Lodha R, and Kapil A et al. Diphtheria down but not out. Indian Paediatrics 2003;37;728-38.

\section{Erratum}

This is in reference to the article titled "Submental tracheal intubation in a case of panfacial trauma" published in KUMJ Vol. 6, No. 1, issue 21, P. 102-4. The correct order of authors and their designation should have been

\section{Babu I', Sagtani $\mathrm{A}^{2}$, Jain $\mathrm{N}^{3}$, Bawa $\mathrm{SN}^{4}$}

${ }^{1,3}$ Assistant Professors, ${ }^{4}$ Professor, Department of Anaesthesiology, ${ }^{2}$ Lecturer, Department of Oral Maxillofacial Surgery, Manipal College of Medical Sciences, Pokhara, Nepal.

Similarly, the correspondence address of Dr. Issac Babu should have been Assistant Professor, Department of Anaesthesiology, Manipal College of Medical Sciences, Pokhara, Nepal Manipal College of Medical Sciences, Pokhara, Nepal.

The mistake in the print issue is highly regretted and the correction will also be amended in the web version of the article. 